\title{
Analisis Pengaruh Beban Tak Seimbang Terhadap Arus Netral Pada Trafo IV GI Sukamerindu Bengkulu
}

\author{
Hendro Tanamal $^{1}$, Afriyastuti Herawati ${ }^{1}$, Novalio Darath ${ }^{1}$, Ika Novia Anggraini ${ }^{1}$ \\ ${ }^{1}$ Program Studi Teknik Elektro Universitas Bengkulu \\ E-mail : hendrounib@gmail.com
}

\begin{abstract}
ABSTRAK
Transformer IV is one of the $20 \mathrm{kV}$ distribution transformers found at the Sukamerindu Bengkulu Substation (GI). The transformer has a power rating of 30 MVA. In distribution transformers, inter-phase load balancing is needed. If the load is not balanced between the phases, current will flow in neutral wire. In this study the effect of unbalanced load on neutral current in transformer IV Sukamerindu Bengkulu is analyzed. The load is analyzed every hour of the day by observing the amount of current and voltage in each phase. From the results of the analysis it was found that the highest neutral current loss value was 1306.25 watts or $1.30 \mathrm{~kW}$ and the lowest was $0.724 \mathrm{~kW}$, with an average neutral current loss that occurred in the IV unit transformer Sukamerindu at 639 watts.
\end{abstract}

\section{PENDAHULUAN}

Saat ini listrik telah menjadi salah satu kebutuhan pokok bagi masyarakat. Untuk menunjang kehidupan sehari-hari, masyarakat sangat tergantung dengan listrik terutama bagi masyarakat yang tinggal di perkotaan. Hampir semua pekerjaan masyarakat dibantu oleh peralatan-peralatan listrik, sehingga sangat dibutuhkan suplai listrik yang kontinyu dan handal. Untuk memenuhi kebutuhan konsumen ini maka penyedia listrik dalam hal ini PT PLN terus melakukan perbaikan dan analisis dalam hal penyaluran listrik.

Penyaluran listrik ke konsumen dari pembangkit, setelah melalui saluran transmisi maka didistribusikan menggunakan transformator tenaga atau biasa disebut trafo di gardu induk (GI). Agar trafo dapat bekerja optimal, maka beban yang disalurkan oleh trafo 3 fasa harus dalam keadaan seimbang. Dalam keadaan seimbang maka beban yang mengalir di tiap kawat fasanya akan sama. Jika beban yang mengalir tidak seimbang antar kawat fasa maka akan mengalir arus di kawat netral yang dapat mengakibatkan rugi-rugi daya di jaringan sehingga akan menyebabkan timbulnya panas pada trafo yang selanjutnya dapat memicu kerusakan pada trafo tenaga.
Penelitian mengenai analisis pengaruh beban tak seimbang terhadap arus netral trafo sudah banyak dilakukan [1][2][3]. Tetapi untuk analisis di Trafo IV Gardu Induk Sukamerindu belum dilakukan. Maka dalam penelitian ini akan dianalisis pengaruh beban tak seimbang terhadap arus setral pada trafo IV GI Sukamerindu Bengkulu.

\section{KERANGKA TEORITIS DAN PENGEMBANGAN HIPOTESIS}

Dalam penyaluran energy listrik diinginkan daya listrik yang disuplai ke beban hampir mendekati nilai sumbernya. Dengan kata lain system penyaluran daya listrik memiliki efisiensi yang tinggi atau rugi-rugi daya yang sedikit. Untuk mendapatkan nilai efisiensi daya yang tinggi maka dalam system 3 fasa dibutuhkan keseimbangan beban antar fasanya.

Adapun syarat suatu system tenaga listrik dikatakan seimbang yaitu :

1. Memiliki besar tegangan yang sama antar fasanya

2. Memiliki beda sudut fasa tegangan sebesar $120^{\circ}$ antar fasanya

3. Memiliki beban yang sama besar antar fasanya

Jika suatu system tenaga tidak memiliki salah satu saja dari syarat tersebut diatas maka system tersebut dapat dikatakan tidak seimbang.

\section{SISTEM TIGA FASA SEIMBANG}

System tiga fasa memiliki 4 bentuk berdasarkan bentuk belitan kawat dari sisi sumber dan bebannya. Bentuk rangkaian tiga fasa tersebut yaitu $\mathrm{Y}$ Y, -Y, Y- dan - Untuk menganalisis arus, tegangan dan daya dalam system yang seimbang maka dapat digunakan persamaan-persamaan (1) sampai dengan persamaan (14). Dalam pembahasan ini hanya akan dibahas mengenai system tiga fasa yang terhubung $\mathrm{Y}-\mathrm{Y}$ dan $-\mathrm{Y}$.

1. System 3 fasa terhubung $Y-Y$

Bentuk rangkaian 3 fasa terhubung Y-Y dapat dilihat pada Gambar 1. 


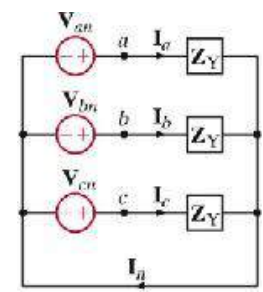

Gambar 1. rangkaian 3 fasa terhubung Y-Y [1]

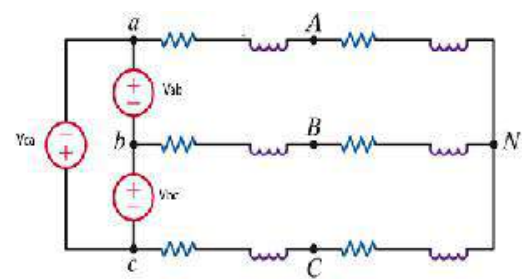

Gambar 2. Bentuk rangkaian 3 fasa terhubung -Y [1]

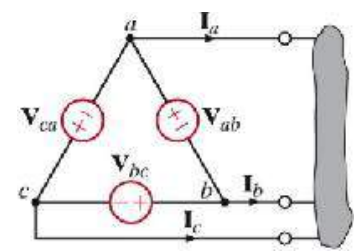

Gambar 3. Bentuk sumber terhubung delta menuju beban yang terhubung Y [1]

Untuk perhitungan arus antar fasanya dapat dihitung menggunakan persamaan (1) [1]

$$
I_{a}=\frac{V_{a n}}{Z_{Y}} \quad I_{b}=\frac{V_{b n}}{Z_{Y}} \quad I_{c}=\frac{V_{c n}}{Z_{Y}}
$$

Untuk system seimbang maka besar masingmasing tegangan adalah :

$$
\begin{array}{ll}
V_{a n}=V_{p} \angle 0^{\circ} & V_{b n}=V_{p} \angle-120^{\circ} \\
V_{c n}=V_{p} \angle 120^{\circ} &
\end{array}
$$

Sehingga dalam system tiga fasa seimbang arus yang mengalir di kawat netral dapat dihitung menggunakan persamaan (2) [1].

$$
I_{n}=I_{a}+I_{b}+I_{c}=0
$$

2. System 3 fasa terhubung $-Y$

Untuk system yang terhubung $-\mathrm{Y}$ dalam rangkaiannya dari sisi sumber terhubung delta dan dari sisi beban terhubung Y. Adapun bentuk rangkaiannya dapat dilihat pada gambar 2 .

Sedangkan bentuk sumbernya dapat dianalisis melalui Gambar 3.

Besar tegangan sumber yaitu :

$$
\begin{array}{ll}
V_{a b}=V_{L} \angle 0^{\circ} & V_{b c}=V_{L} \angle-120^{\circ} \\
V_{c a}=V_{L} \angle 120^{\circ} &
\end{array}
$$

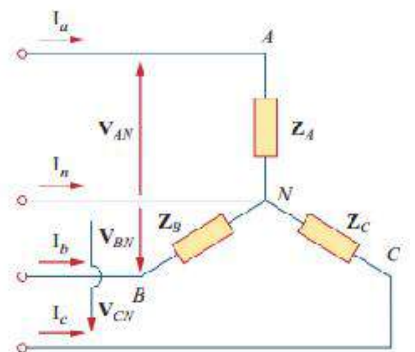

Gambar 4. Bentuk rangkaian tiga fasa tidak seimbang [1]

Maka untuk mendapatkan besar arus di kawat penghantar tegangan saluran dari sumber dikonversikan terlebih dahulu ke dalam bentuk tegangan fasa (fasa ke netral bentuk Y) melalui persamaan (3) [1].

$$
\begin{aligned}
& V_{a n}=\frac{V_{L}}{\sqrt{3}} \angle-30^{\circ} V_{b n}=\frac{V_{L}}{\sqrt{3}} \angle-150^{\circ} \\
& V_{c n}=\frac{V_{L}}{\sqrt{3}} \angle 90^{\circ}
\end{aligned}
$$

Maka besar arus $I_{a}, I_{b}$ dan $I_{c}$ dapat dihitung menggunakan persamaan (1).

\section{DAYA PADA RANGKAIAN 3 FASA}

Besar daya aktif pada rangkaian 3 fasa seimbang dapat dihitung menggunakan persamaan (4) atau (5) [1].

$$
\begin{aligned}
& P=3 V_{p} I_{p} \cos \varphi \\
& P=\sqrt{3} V_{L} I_{L} \cos \varphi
\end{aligned}
$$

\section{SISTEM 3 FASA TIDAK SEIMBANG}

Suatu sistem tiga fasa dikatakan tidak seimbang apabila :

1. Sumber tegangannya tidak sama nilainya

2. perbedaan sudut fasa tidak sama (beda fasa tidak $120^{\circ}$ )

3. Impedansi beban tidak sama

Untuk menganalisis beban pada system tidak seimbang maka dapat dilihat pada Gambar 4. Pada system tiga fasa tidak seimbang, besar arus pada tiap kawatnya harus dihitung perfasanya. Arus perfasa pada system tidak seimbang dapat dihitung menggunakan persamaan (6)[1].

$$
\begin{array}{rlr}
I_{a}=\frac{V_{a n}}{Z_{A}} & I_{b}=\frac{V_{b n}}{Z_{B}} \\
I_{c}=\frac{V_{c n}}{Z_{C}} & \text { (6) }
\end{array}
$$

Dalam system tiga fasa tidak seimbang maka pada kawat netral akan ada arus yang mengalir dari masing- 
masing kawat fasa. Artinya besar arus di kawat netral tidak lagi bernilai 0. Besar arus netral ini dihitung menggunakan persamaan (7) [1].

$$
I_{n}=-\left(I_{a}+I_{b}+I_{c}\right) \neq 0
$$

Maka besar daya ditiap kawat fasanya juga harus dihitung satu persatu perfasanya. Perhitungannya dapat dihitung menggunakan persamaan (8), (9) dan (10)[1].

$$
\begin{gathered}
P_{a}=V_{a n} I_{a} \cos \varphi \\
P_{b}=V_{b n} I_{b} \cos \varphi \\
P_{c}=V_{c n} I_{c} \cos \varphi
\end{gathered}
$$

\section{PERHITUNGAN ARUS BEBAN PENUH DAN ARUS HUBUNG SINGKAT PADA TRAFO}

Daya transformator distribusi ditinjau dari sisi tegangan tinggi (primer) dapat dirumuskan melalui persamaan (11)[2].

$$
S=\sqrt{3} V_{L} I_{L}
$$

Dimana :

$\mathrm{S}$ : daya transformator (kVA)

$\mathrm{V}_{\mathrm{L}}$ :tegangan sisi primer transformator $(\mathrm{kV})$

$\mathrm{I}_{\mathrm{L}}$ : arus jala-jala (A)

Dengan demikian, untuk menghitung arus beban penuh (fullload) dapat menggunakan persamaan (12) [2].

$$
I_{F L}=\frac{S}{\sqrt{3 V_{L}}}
$$

Dimana :

$\mathrm{I}_{\mathrm{FL}}$ : arus beban penuh $(\mathrm{A})$

$\mathrm{S}$ : daya transformator $(\mathrm{kVA})$

$\mathrm{V}_{\mathrm{L}}$ : tegangan sisi sekunder transformator $(\mathrm{kV})$

Sedangkan untuk menghitung arus hubung singkat pada transformator digunakan persamaan (13)[2].

$$
I_{S C}=\frac{S .100}{\% Z V_{L}}
$$

Dimana :

$\mathrm{I}_{\mathrm{SC}}$ : arus hubung singkat (A)

$\mathrm{S}$ : daya transformator (kVA)

$\mathrm{V}$ : tegangan sisi sekunder transformator(kV)

$\%$ Z:persen impedansi transformator

\section{Losses (rugi-rugi) Akibat Adanya arus Netral pada Penghantar Netral Transformator}

Sebagai akibat dari ketidakseimbangan beban antara tiap-tiap fasa pada sisi sekunder trafo (fasaR, S, dan T) mengalirlah arus dinetral trafo. Arus yang mengalir pada penghantar netral trafo ini menyebabkan losses (rugi-rugi). Losses pada penghantar netral trafo ini dapat dirumuskan melalui persamaan (14)[2].

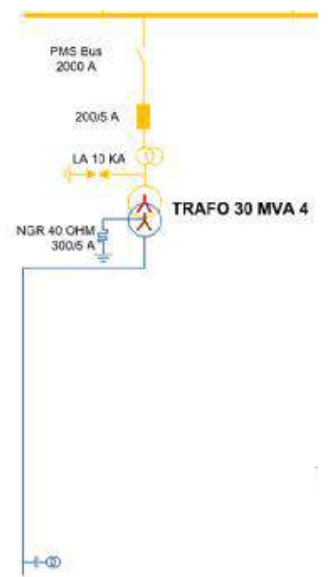

Gambar.5 Single line diagram trafo daya IV GI Sukamerindu, Bengkulu [2].

$$
P_{N}=I_{N}^{2} \cdot R_{N}
$$

Dimana :

$\mathrm{P}_{\mathrm{N}}$ : losses pada penghantar netral trafo(Watt)

$\mathrm{I}_{\mathrm{N}}$ : arus yang mengalir pada netraltrafo (A)

$\mathrm{R}_{\mathrm{N}}$ : tahanan penghantar netral trafo( )

Sedangkan losses yang diakibatkan karena arus netral yang mengalir ketanah (ground) dapat dihitung melalui persamaan (15)[2].

$$
P_{G}=I_{G}^{2} \cdot R_{G}
$$

Dimana :

$\mathrm{P}_{\mathrm{G}}$ : losses akibat arus netral yangmengalir ke tanah (Watt)

$\mathrm{I}_{\mathrm{G}}$ : arus netral yang mengalir ke $\operatorname{tanah}(\mathrm{A})$

$\mathrm{R}_{\mathrm{G}}$ : tahanan pembumian netral trafo( )

\section{METODE RISET}

Penelitian dilakukan dengan melakukan pengumpulan data dan analisa rugi daya yang terdiri dari rugi arus netral, rugi daya inti dan rugi daya belitan pada transformator tenaga IV yang berada di GI Sukamerindu, Bengkulu.

Objek penelitian yang digunakan adalah Transformator tenaga unit IV penyaluran penyulang wilayah Pulau Baii, Tambak udang, Basuki Rahmat, Kembang Seri dan sekitarnya.

Adapun single line diagram dari trafo daya GI Sukamerindu.

Gambar 5 merupakan single line diagram dari salah satu trafo daya, yaitu trafo daya unit IV di GI Sukamerindu, Bengkulu.

Arus netral merupakan arus yang mengalir pada kawat netral akibat adanya suatu gangguan salah satunya ketidakseimbangan beban. Ketidakseimbangan beban disin menyebabkan arus tiap-tiap fasa menjadi tidak seimbang. Adapun standar ketidakseimbangan arus 
Tabel 1 Data beban, tegangan dan arus trafo tenaga di GI Sukamerindu.
Analisa Arus Beban Penuh dan (\%) Pembebanan Hari: Selasa 14-02-2017

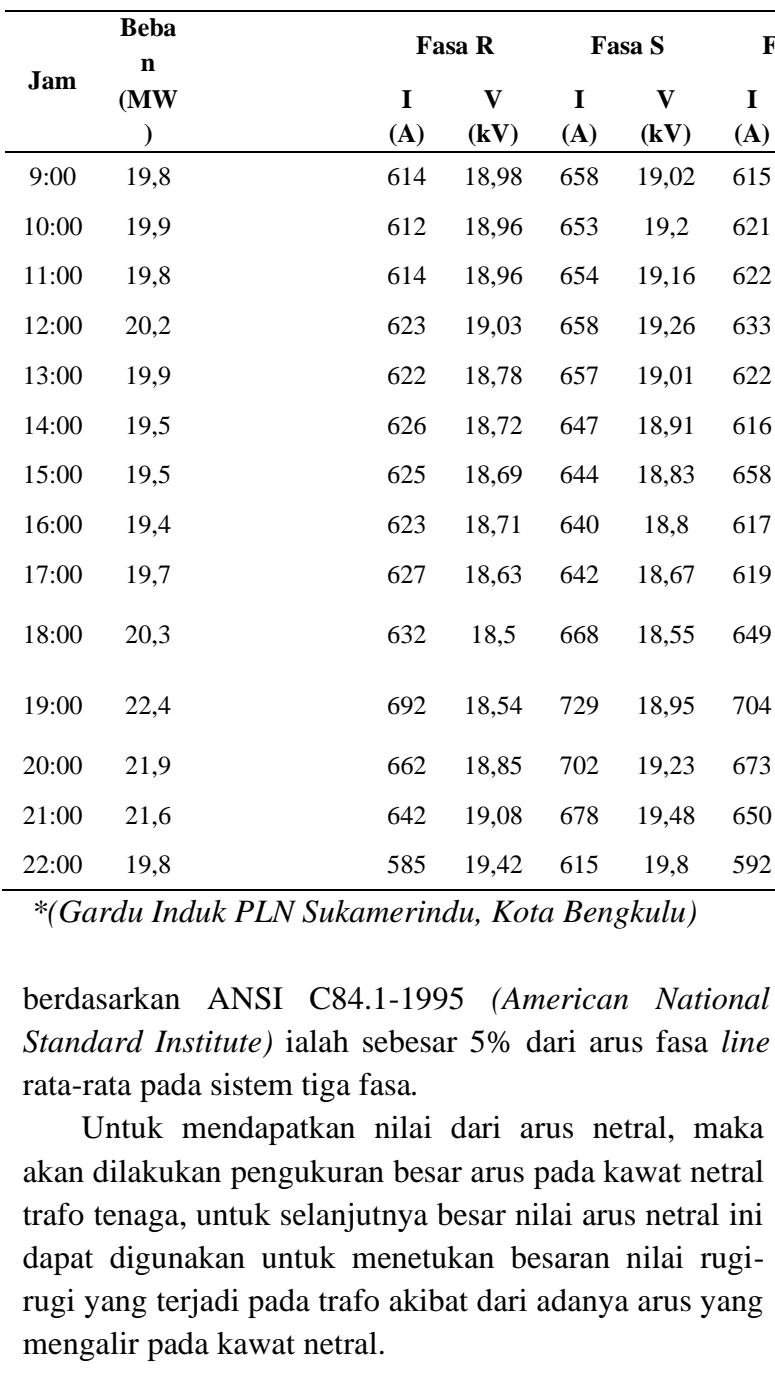

\section{HASIL DAN PEMBAHASAN}

Pembebanan pada transformator sangat berpengaruh terhadap besar atau kecilnya rugi-rugi daya yang terjadi pada trafo. Idealnya, untuk meminimalisir rugi-rugi pada kawat netral dan kawat netral, trafo diberikan beban yang seimbang. Untuk melihat besar pembebanan pada trafo tenaga di GI Sukamerindu, Bengkulu maka dilakukan persentase pembebanan pada trafo.

\section{Analisa Arus Beban Penuh dan Persentase Pembebanan Pada Transformator Tenaga}

Arus beban penuh dihitung terlebih dahulu, selanjutnya dapat menentukan persentase pembebanan. Persentase pembebanan pada transformator tenaga dianalisa setiap hari dari lima hari sampel data yang digunakan.
Persentase pembebanan dihitung berdasarkan Fasa T pada Tabel 4.4. Pada tabel tersebut, dapat dilihat data (kV) pembebanan, arus dan tegangan tiga fasa $(\mathrm{R}, \mathrm{S}, \mathrm{T})$ pada 5 18,33 trafo yang terukur dengan rekapan setiap jam dimulai 18,78 dari pukul 09.00 s.d 22.00. 18,77 dihitung, dilakukan perhitungan arus beban penuh 18,9 erlebih dahulu, kemudian dihitung persentase 622 18,5 pebebanan pada setiap fasa, setelah itu persentase 1618,5 pebebanan setiap fasa dirata-ratakan.

58 Tabel 1 merupakan data beban, tegangan dan 17 19,75 arus trafo tenaga di GI Sukamerindu. Berdasarkan data 18,0 pada Tabel 1 maka dapat dilakukan analisa pembebanan

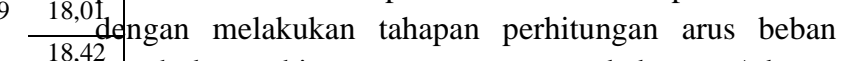
${ }_{9}^{8,42}$ penuh dan perhitungan persentase pembebanan. Adapun 18,5perhitungannya sebagai berikut :

2 a. Perhitungan Arus Beban Penuh

$673 \quad$ Perhitungan arus beban penuh ini dilakukan 650 19,03erlebih dahulu sebelum dapat ditentukan besar nilai $92 \quad$ 19,3persentase pembebanannya. Data yang dibutuhkan ialah rating daya trafo yakni sebesar 30 MVA dan tegangan keluaran sebesar $20 \mathrm{KV}$ pada trafo tenaga unit IV GI Sukamerindu, Bengkulu. Perhitungan arus beban penuh (Ifl) dengan menggunakan Persamaan (2.6) pada tinjauan pustaka.

Adapun perhitungannya sebagai berikut:

$$
\mathrm{I} f l=\frac{30000000 \mathrm{VA}}{\sqrt{3} \times 20000 \mathrm{~V}}=867,05 \mathrm{~A}
$$

Dari hasil perhitungan arus beban penuh dapat dilihat nilai arus beban penuh terbesar pada trafo yakni sebesar 867,05A. Setelah didapatkan besar nilai arus beban penuh dari trafo, maka dapat dilakukan analisa pembebanan trafo.

b. Perhitungan Persentase Pembebanan

Berdasarkan hasil perhitungan Arus beban penuh yang telah dilakukan, maka dapat ditentukan besar persentase pembebanan. Perhitungan persentase pembebanannya sebagai berikut :

- Perhitungan persentase beban Pada Phasa R,S,T (pada beban puncak)

Perhitungan rata - rata persentase pembebanan dilakukan pada fasa (R,S,T),

Adapun perhitungannya sebagai berikut:

- $\% \mathrm{bR}=\frac{692}{867,05} \times 100 \%=79,81 \%$

- $\% b S=84,08 \%$

- $\% b T=81,19 \%$

- $\% b($ rata - rata $)$ $\frac{79,81 \%+84,08 \%+81,19 \%}{3}=81,69$ $\frac{18,78}{18,77}$ Adapun sebelum persentase pembebanan dapat 


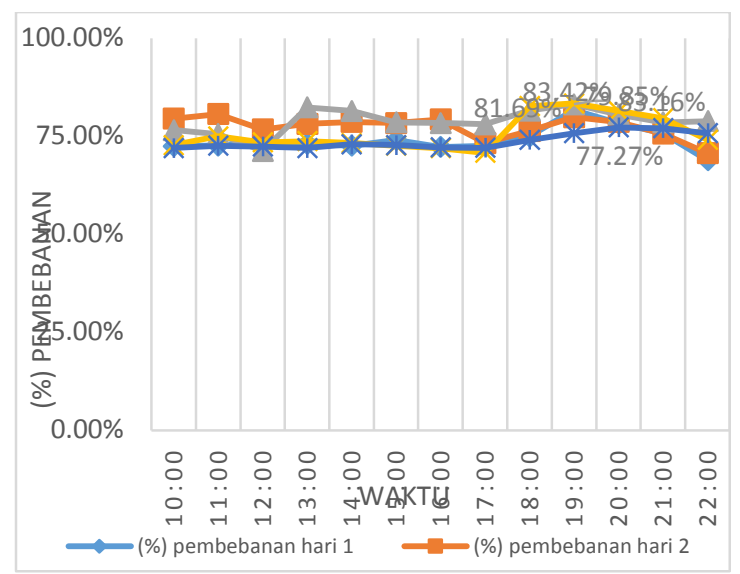

Gambar 6 Grafik perbandingan antara persentase pembebanan terhadap waktu

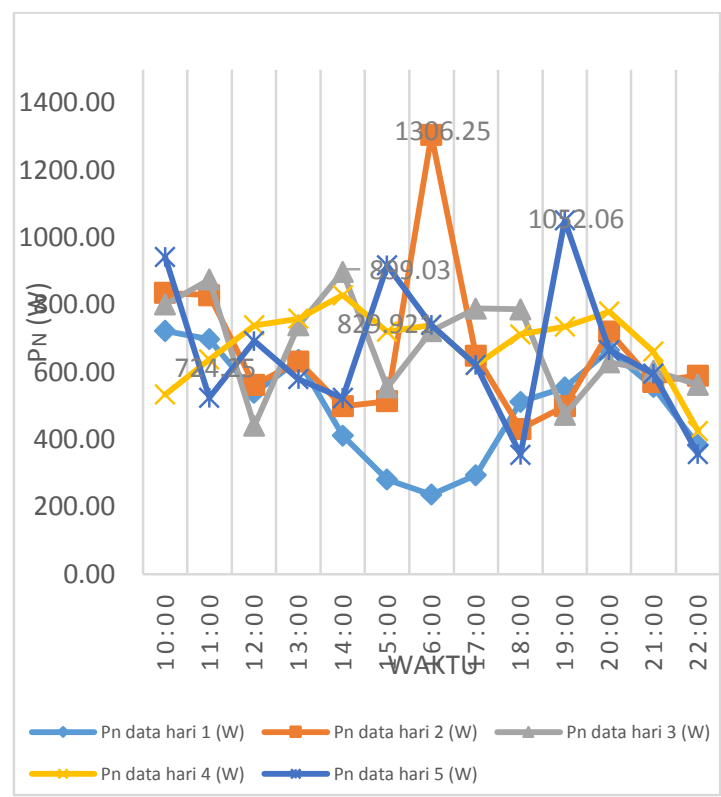

Gambar 7. Grafik perbandingan rugi arus netral (PN) terhadap waktu

Gambar 6 menunjukkan grafik perbandingan antara persentase pembebanan terhadap waktu pada saat pengambilan data dimulai dari pukul 09:00 s.d 22:00 selama lima hari sampel yang diambil, dapat dilihat persentase pembebanan tertinggi dari data yang dianalisis ialah sebesar $83.42 \%$ dan yang terendah sebesar $77,27 \%$.

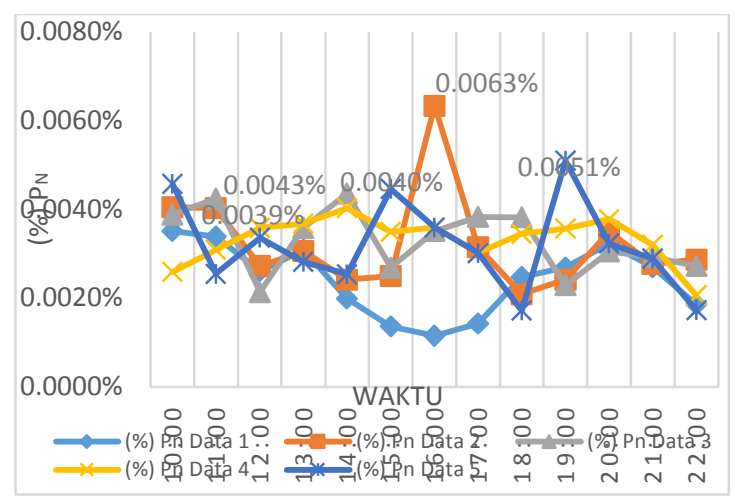

Gambar 8. Grafik Persentase rugi arus netral persentase PN terhadap waktu

Saat dirata-ratakan, maka didapatkan persentase pembebanan setiap harinya, yaitu rata-rata sebesar $81.08 \%$. Setelah analisa persentase pembebanan dilakukan, selanjutnya bisa dilakukan analisa ketidakseimbangan beban pada trafo tenaga di GI Sukamerindu, Bengkulu.

Berdasarkan data dapat dilihat bahwa nilai rugi arus netral dan besar persentase ketidakseimbangan beban dapat dilihat pula bahwa semakin besar ketidakseimbangan beban, maka rugi arus netral yang ditimbulkan juga semakin besar.

Berikut Gambar.4.7, yaitu grafik rugi arus netral terhadap waktu.

Gambar 7 menunjukkan grafik perbandingan rugi arus netral (PN) terhadap waktu. Berdasarkan Gambar 7 dapat dilihat bahwa nilai rugi arus netral tertinggi didapatkan sebesar 1306.25 watt atau $1.30 \mathrm{~kW}$ dan yang terendah ialah sebesar $0.724 \mathrm{~kW}$, dengan rata-rata rugi arus netral yang terjadi pada trafo unit IV GI Sukamerindu sebesar 639 watt. Adapun grafik persentase rugi arus netral seperti pada Gambar 8 .

Gambar 8 menunjukkan Grafik Persentase rugi arus netral persentase PN terhadap waktu. Adapun besar persentase rugi arus netral tertinggi ialah $0.0063 \%$ dan terendah $0,0035 \%$, dengan rata-rata persentase ruginya sebesar $0,0031 \%$. Persentase rugi arus netral berbanding lurus dengan persentase ketidakseimbangan beban netral yang ditimbulkan, ini menunjukkan semakin besar persentase ketidak-seimbangan beban, maka rugi arus netral juga ikut semakin besar 
Tabel 2 Data hasil perhitungan rugi arus netral trafo daya unit IV GI Sukamerindu, Bengkulu

\begin{tabular}{|c|c|c|c|c|c|c|c|c|c|c|c|c|c|c|c|c|c|c|c|c|}
\hline \multirow[b]{2}{*}{ jam } & \multicolumn{4}{|c|}{ Data Hari Selasa 14 -02- 2017} & \multicolumn{4}{|c|}{ Data Hari Kamis 16 -02- 2017} & \multicolumn{4}{|c|}{ Data Hari Jumat 17 -02- 2017} & \multicolumn{4}{|c|}{ Data Hari Senin 20 -02- 2017} & \multicolumn{4}{|c|}{ Data Hari Selasa 21-02- 2017} \\
\hline & $\begin{array}{c}(\%) \\
\text { Beban }\end{array}$ & $\begin{array}{c}(\%) \\
\text { B.unb }\end{array}$ & $\begin{array}{c}\mathbf{P N}_{\mathrm{N}} \\
\text { (watt) }\end{array}$ & $\begin{array}{l}(\%) \\
P_{N}\end{array}$ & $\begin{array}{c}(\%) \\
\text { Beban }\end{array}$ & $\begin{array}{c}(\%) \\
\text { B.unb }\end{array}$ & $\begin{array}{c}\mathbf{P N}_{\mathrm{N}} \\
\text { (watt) }\end{array}$ & $\begin{array}{l}(\%) \\
P_{N}\end{array}$ & $\begin{array}{c}(\%) \\
\text { Beban }\end{array}$ & $\begin{array}{c}(\%) \\
\text { B.unb }\end{array}$ & $\begin{array}{c}\mathbf{P N}_{\mathrm{N}} \\
\text { (watt) }\end{array}$ & $\begin{array}{l}(\%) \\
P_{N}\end{array}$ & $\begin{array}{c}(\%) \\
\text { B.unb }\end{array}$ & $\begin{array}{c}(\%) \\
\text { Beban }\end{array}$ & $\begin{array}{c}\mathbf{P N}_{\mathbf{N}} \\
\text { (watt) }\end{array}$ & $\begin{array}{l}(\%) \\
P_{N}\end{array}$ & $\begin{array}{c}(\%) \\
\text { Beba } \\
\text { n }\end{array}$ & $\begin{array}{c}(\%) \\
\text { B.unb }\end{array}$ & $\begin{array}{c}\mathbf{P N}_{\text {N }} \\
\text { (watt) }\end{array}$ & $\begin{array}{l}(\%) \\
P_{N}\end{array}$ \\
\hline 10:00 & $72.51 \%$ & $2.58 \%$ & 724.25 & $\begin{array}{c}0.0035 \\
\%\end{array}$ & $\begin{array}{c}78 \\
.77 \%\end{array}$ & $2.48 \%$ & 836.58 & $\begin{array}{c}0.0041 \\
\%\end{array}$ & $76.62 \%$ & $2.58 \%$ & 802.32 & $\begin{array}{c}0.0039 \\
\%\end{array}$ & $2.22 \%$ & $72.78 \%$ & 535.146 & $\begin{array}{c}0.0026 \\
\%\end{array}$ & $\begin{array}{c}72.01 \\
\%\end{array}$ & $2.95 \%$ & 942.79 & $\begin{array}{c}0.0046 \\
\%\end{array}$ \\
\hline 11:00 & $72.66 \%$ & $2.54 \%$ & 698.86 & $\begin{array}{c}0.0034 \\
\%\end{array}$ & $79.46 \%$ & $2.51 \%$ & 830.34 & $\begin{array}{c}0.0040 \\
\%\end{array}$ & $75.62 \%$ & $2.68 \%$ & 877.11 & $\begin{array}{c}0.0043 \\
\%\end{array}$ & $2.41 \%$ & $75.01 \%$ & 638.092 & $\begin{array}{c}0.0031 \\
\%\end{array}$ & $\begin{array}{c}72.54 \\
\%\end{array}$ & $2.23 \%$ & 525.84 & $\begin{array}{c}0.0026 \\
\%\end{array}$ \\
\hline 12:00 & $73.58 \%$ & $2.09 \%$ & 539.83 & $\begin{array}{c}0.0026 \\
\%\end{array}$ & $76.12 \%$ & $2.11 \%$ & 563.20 & $\begin{array}{c}0.0027 \\
\%\end{array}$ & $71.28 \%$ & $2.05 \%$ & 441.55 & $\begin{array}{c}0.0021 \\
\%\end{array}$ & $2.55 \%$ & $73.43 \%$ & 739.855 & $\begin{array}{c}0.0036 \\
\%\end{array}$ & $\begin{array}{c}72.39 \\
\%\end{array}$ & $2.48 \%$ & 693.15 & $\begin{array}{c}0.0034 \\
\%\end{array}$ \\
\hline 13:00 & $73.08 \%$ & $2.45 \%$ & 637.36 & $\begin{array}{c}0.0031 \\
\%\end{array}$ & $77.16 \%$ & $2.09 \%$ & 632.28 & $\begin{array}{c}0.0031 \\
\%\end{array}$ & $82.42 \%$ & $2.27 \%$ & 739.86 & $\begin{array}{c}0.0036 \\
\%\end{array}$ & $2.40 \%$ & $73.81 \%$ & 759.600 & $\begin{array}{c}0.0037 \\
\%\end{array}$ & $\begin{array}{c}72.01 \\
\%\end{array}$ & $2.31 \%$ & 580.79 & $\begin{array}{c}0.0028 \\
\%\end{array}$ \\
\hline 14:00 & $72.62 \%$ & $1.87 \%$ & 412.35 & $\begin{array}{c}0.0020 \\
\%\end{array}$ & $78.20 \%$ & $1.92 \%$ & 499.72 & $\begin{array}{c}0.0024 \\
\%\end{array}$ & $81.50 \%$ & $3.07 \%$ & 899.03 & $\begin{array}{c}0.0044 \\
\%\end{array}$ & $2.73 \%$ & $73.24 \%$ & 829.921 & $\begin{array}{c}0.0040 \\
\%\end{array}$ & $\begin{array}{c}73.01 \\
\%\end{array}$ & $2.11 \%$ & 524.19 & $\begin{array}{c}0.0025 \\
\%\end{array}$ \\
\hline $15: 00$ & $74.08 \%$ & $1.59 \%$ & 282.30 & $\begin{array}{c}0.0014 \\
\%\end{array}$ & $77.73 \%$ & $1.99 \%$ & 515.32 & $\begin{array}{c}0.0025 \\
\%\end{array}$ & $78.58 \%$ & $2.02 \%$ & 556.03 & $\begin{array}{c}0.0027 \\
\%\end{array}$ & $2.51 \%$ & $72.58 \%$ & 721.145 & $\begin{array}{c}0.0035 \\
\%\end{array}$ & $\begin{array}{c}72.81 \\
\%\end{array}$ & $2.85 \%$ & 919.03 & $\begin{array}{c}0.0045 \\
\%\end{array}$ \\
\hline 16:00 & $72.28 \%$ & $1.45 \%$ & 237.69 & $\begin{array}{c}0.0012 \\
\%\end{array}$ & $78.77 \%$ & $3.26 \%$ & $\begin{array}{c}1306.2 \\
5\end{array}$ & $\begin{array}{c}0.0063 \\
\%\end{array}$ & $78.39 \%$ & $2.39 \%$ & 724.25 & $\begin{array}{c}0.0035 \\
\%\end{array}$ & $2.67 \%$ & $71.97 \%$ & 741.033 & $\begin{array}{c}0.0036 \\
\%\end{array}$ & $\begin{array}{c}72.20 \\
\%\end{array}$ & $2.67 \%$ & 741.03 & $\begin{array}{c}0.0036 \\
\%\end{array}$ \\
\hline $17: 00$ & $72.58 \%$ & $1.58 \%$ & 294.80 & $\begin{array}{c}0.0014 \\
\%\end{array}$ & $72.43 \%$ & $2.41 \%$ & 650.54 & $\begin{array}{c}0.0032 \\
\%\end{array}$ & $78.04 \%$ & $2.50 \%$ & 789.70 & $\begin{array}{c}0.0038 \\
\%\end{array}$ & $2.39 \%$ & $70.81 \%$ & 622.523 & $\begin{array}{c}0.0030 \\
\%\end{array}$ & $\begin{array}{c}72.08 \\
\%\end{array}$ & $2.39 \%$ & 622.52 & $\begin{array}{c}0.0030 \\
\%\end{array}$ \\
\hline 18:00 & $74.93 \%$ & $1.88 \%$ & 512.37 & $\begin{array}{c}0.0025 \\
\%\end{array}$ & $71.74 \%$ & $2.01 \%$ & 432.21 & $\begin{array}{c}0.0021 \\
\%\end{array}$ & $81.58 \%$ & $2.32 \%$ & 788.49 & $\begin{array}{c}0.0038 \\
\%\end{array}$ & $2.23 \%$ & $82.69 \%$ & 713.035 & $\begin{array}{c}0.0035 \\
\%\end{array}$ & $\begin{array}{c}74.04 \\
\%\end{array}$ & $1.66 \%$ & 355.59 & $\begin{array}{c}0.0017 \\
\%\end{array}$ \\
\hline 19:00 & $81.69 \%$ & $1.95 \%$ & 556.03 & $\begin{array}{c}0.0027 \\
\%\end{array}$ & $79.35 \%$ & $1.89 \%$ & 499.72 & $\begin{array}{c}0.0024 \\
\%\end{array}$ & $83.16 \%$ & $1.85 \%$ & 474.26 & $\begin{array}{c}0.0023 \\
\%\end{array}$ & $2.27 \%$ & $83.42 \%$ & 736.720 & $\begin{array}{c}0.0036 \\
\%\end{array}$ & $\begin{array}{c}75.74 \\
\%\end{array}$ & $3.10 \%$ & $\begin{array}{c}1052.0 \\
6\end{array}$ & $\begin{array}{c}0.0051 \\
\%\end{array}$ \\
\hline 20:00 & $78.31 \%$ & $2.26 \%$ & 666.08 & $\begin{array}{c}0.0032 \\
\%\end{array}$ & $78.08 \%$ & $2.31 \%$ & 721.15 & $\begin{array}{c}0.0035 \\
\%\end{array}$ & $80.58 \%$ & $2.13 \%$ & 630.83 & $\begin{array}{c}0.0031 \\
\%\end{array}$ & $2.30 \%$ & $81.46 \%$ & 780.410 & $\begin{array}{c}0.0038 \\
\%\end{array}$ & $\begin{array}{c}77.27 \\
\%\end{array}$ & $2.29 \%$ & 666.08 & $\begin{array}{c}0.0032 \\
\%\end{array}$ \\
\hline 21:00 & $75.74 \%$ & $2.17 \%$ & 557.39 & $\begin{array}{c}0.0027 \\
\%\end{array}$ & $74.62 \%$ & $2.24 \%$ & 572.47 & $\begin{array}{c}0.0028 \\
\%\end{array}$ & $78.54 \%$ & $2.15 \%$ & 605.37 & $\begin{array}{c}0.0029 \\
\%\end{array}$ & $2.09 \%$ & $79.62 \%$ & 661.992 & $\begin{array}{c}0.0032 \\
\%\end{array}$ & $\begin{array}{c}77.08 \\
\%\end{array}$ & $2.16 \%$ & 596.53 & $\begin{array}{c}0.0029 \\
\%\end{array}$ \\
\hline 22:00 & $68.89 \%$ & $1.97 \%$ & 384.43 & $\begin{array}{c}0.0019 \\
\%\end{array}$ & $69.89 \%$ & $2.39 \%$ & 591.26 & $\begin{array}{c}0.0029 \\
\%\end{array}$ & $78.89 \%$ & $1.88 \%$ & 563.54 & $\begin{array}{c}0.0027 \\
\%\end{array}$ & $1.97 \%$ & $74.12 \%$ & 425.934 & $\begin{array}{c}0.0021 \\
\%\end{array}$ & $\begin{array}{c}75.74 \\
\%\end{array}$ & $1.76 \%$ & 357.22 & $\begin{array}{c}0.0017 \\
\%\end{array}$ \\
\hline
\end{tabular}




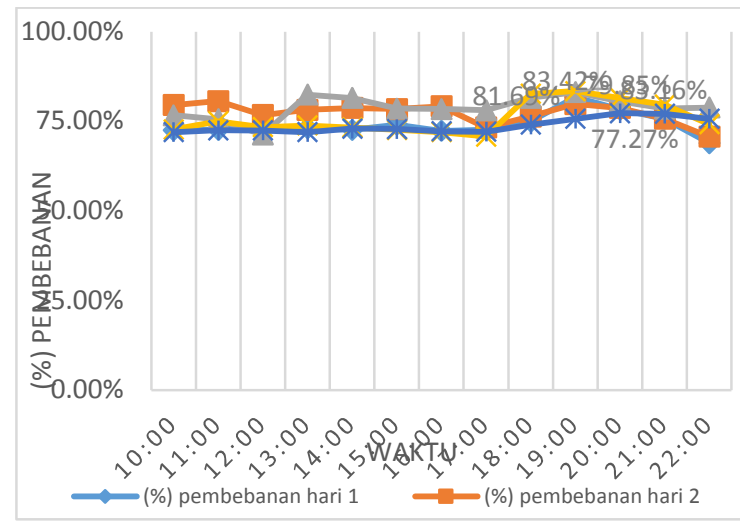

Gambar 9. Grafik perbandingan antara

persentase pembebanan terhadap waktu

Berdasarkan Tabel 2 Data hasil perhitungan (\%) pembebanan, maka dapat dilihat bahwa dari perhitungan yang dilakukan, diketahui persentase pembebanan tertinggi ialah sebesar $81.69 \%$ dan dengan yang terendah ialah sebesar $68.89 \%$.

Dari Tabel data hasil perhitungan diatas juga dapat dibuat grafik persentase persentase pembebanan terhadap waktu. Berikut Gambar 9 Grafik persentase pembebanan.

Gambar 9 menunjukkan grafik perbandingan antara persentase pembebanan terhadap waktu pada saat pengambilan data dimulai dari pukul 09:00 s.d 22:00 selama lima hari sampel yang diambil, dapat dilihat persentase pembebanan tertinggi dari data yang dianalisis ialah sebesar $83.42 \%$ dan yang terendah sebesar $77,27 \%$.

Saat dirata-ratakan, maka didapatkan persentase pembebanan setiap harinya, yaitu rata-rata sebesar $81.08 \%$. Setelah analisa persentase pembebanan dilakukan, selanjutnya bisa dilakukan analisa ketidakseimbangan beban pada trafo tenaga di GI Sukamerindu, Bengkulu.

\section{KESIMPULAN}

Dari hasil analisis didapatkan bahwa trafo IV Sukamerindu terdapat arus netral yang mengalir yang artinya bahwa kondisinya dalam keadaan tidak seimbang. Rugi arus netral rata-rata pada transformator unit IV GI Sukamerindu, didapatkan sebesar 639 watt. Rugi arus netral yang terjadi pada transformator unit IV GI Sukamerindu, Bengkulu tidak membahayakan sistem, karena rugi yang dihasilkan cukup kecil, dengan persentase rugi arus netral rata-rata hanya sebesar $0,0031 \%$ dari daya transformator rata-rata 20,62 MW.

\section{REFERENSI}

[1] Nazarudin, "Analisis Aliran Beban Tak Seimbang Pada Jaringan Distribusi Sistem Radial Feeder Lk 07 Sistem Kelistrikan Lhokseumawe", Prosiding Seminar Nasional Politeknik Negeri Lhokseumawe, Aceh, 2018.

[2] Sogen, Markus Dwiyanto Tobi, "Analisis Pengaruh Ketidakseimbangan Beban Terhadap Arus Netral Dan Losses Pada Transformator Distribusi Di Pt Pln (Persero) Area Sorong", Jurnal Electro Luceat Vol. 4 No. 1 Juli 2018, Sorong, 2018.

[3] Gamma Ayu Kartika Sari, "Analisa Pengaruh Ketidakseimbangan Beban Terhadap Arus Netral Dan Losses Pada Trafo Distribusi Studi Kasus Pada Pt. Pln (Persero) Rayon Blora”, Skripsi, Program Studi Teknik Elektro Fakultas Teknik Universitas Muhammadiyah Surakarta, 2018.

[4] Charles K Alexander, Matthew N.O Sadiku,'Fundamentals of electric circuits $4^{\text {th }}$ edition”, , 2009, Mc Graw Hill.

[5] Sudaryatno Sudirham,1991.Pengaruh Ketidakseimbangan ArusTerhadap Susut Daya padaSaluran, Bandung: ITB, TimPelaksana KerjasamaPLN-ITB 